\title{
Memory as Material of the Project of Sustainability
}

\author{
Sebastiano D'Urso \\ Department of Civil Engineering and Architecture, University of Catania, Via Santa Sofia 64, 95123 Catania, Italy; \\ sebastiano.durso@unict.it; Tel.: +39-349-4787-490
}

Received: 14 April 2020; Accepted: 13 May 2020; Published: 18 May 2020

\begin{abstract}
The concept of sustainability is multidimensional and includes institutional, social, cultural, environmental, and economic dimensions. It shows the extent to which humans and the environment are interdependent. The multidisciplinary drive of research applied to sustainability, therefore, stems from the awareness of an interconnected world. Man, endowed with the gift of memory, establishes with the environment mnemonic relationships, from recollections to oblivion. Memory also protects us from past events because we remember the perceptions and feelings experienced during personal or collective circumstance. Starting from this perspective, a reflection is proposed on how memory, as a tool and measure of human knowledge, can offer solutions to both the problem of sustainability and to the development of processes and projects based on shared values. The concept of memory can also include things or objects as they store knowledge, meanings and memories to be discovered. The various forms memory takes, are to be considered the material through which man decodes and builds time and space. Hence, memory has always been the bedrock of sustainability as it works as a common theme across generations until its goals are achieved. In space, these mnemonic relationships are manifest in terms of heritage and nature. Nonetheless, the outcome of these considerations is that in order to use memory as an instrument of the project of sustainability it is necessary to redefine, through their interconnections, the concepts of both memory and sustainability.
\end{abstract}

Keywords: unsustainable architecture; sustainability paradigms; environmental memory; greenwashing

\section{Introduction}

Sustainability as an idea of development, which seeks an equilibrium for better management of our planet's resources and to fulfill the purpose of sustainability, involves a growing number of dimensions, namely, the institutional, cultural, social, environmental, economic, and technological ones. This multidimensional expansion of the concept of sustainability [1] might also prevent those approaches to economic development typical of mainstream views of sustainability from causing further damage. The different dimensions which can be defined in terms of indexes of the level of sustainability [2] represent the complexity [3] it involves. No dimension is self-contained, nor can they be separated from the others. All dimensions depend on the same system of relationships, in other words, an integrated $[4,5]$ or holistic $[6,7]$ approach to sustainable development. Hence, multidimensionality is the synthesis of the current paradigm of sustainability. Studies drawing on the disciplines that deal with complexities in the domain of sustainability [3], highlight the interdependence of the problems involved, meaning that solutions must not overlook their intricate interconnectivity, both in terms of quantity and diversity. For this reason, it is not possible to appreciate the complexity of sustainability from an evaluation of the different singularities only, because it is their interdependence that transforms pluralities in something altogether different from the simple sum of all its parts [8]. A different way to define and explain complexity is Alan Berthoz's "simplexity." This simplification, Alain Berthoz argues, encapsulates the concept of biological necessity, that, for the sake of human survival, we must find solutions to complex problems starting from simplifying 
principles based on past experiences but capable of protecting us from the future [9]. Hence, regardless of the way or ways we choose to describe reality, in terms of complexities or "simplexities," the reality is still created through relationships and interconnections. Among these relationships, the ones man establishes with the environment should also be taken into account, be these relationships material or immaterial, including mnemonic ones. Endowed with the gift of memory in fact [10-12], man weaves mnemonic relationships with the reality that surrounds the individual and the collectivity, and on these constructs, identity and culture are built $[10,11,13]$. Moreover, memory helps not to repeat past mistakes. As such, memory can be seen as a pro-sustainability tool. Memories become dynamic materials, which, unlike history [12], activate cognitive processes of knowledge and awareness through which humans can be better equipped to face their current problems. Nevertheless, we should not overlook the fact that memory and forgetfulness are the two sides of the same coin [14,15]. Oblivion, in fact, dissolves memories paving the way for new ones. It also tends to remove negative actions or outcomes we prefer to forget $[16,17]$ to protect our moral image and psychological well-being. After this overview on the relevance of relationships, memories, and amnesia, I will discuss positions and proposals arising from research on sustainable development [10-12] and memory [13-20], to show the extent to which the latter has contributed and keeps contributing to the construction of the sustainability paradigm.

The considerations presented here to the reader and the scholar aim at answering the objectives of this article following the methodological approach as in Section 2.

The results of the theoretical speculations and experimental verifications are presented in three separate sub-sections where the distance between theoretical positions and the design practices that should interpret them are highlighted. In Section 3.1, I will analyze through the lens of mnemonic processes some proposals aiming at the resolution of today's environmental problems. Human constructions, from single urban architectures to huge infrastructures and facilities compound the environmental problem. The issue of sustainability, therefore, involves also the project and vision of an architecture whose objectives are a better world in terms of energy consumption, beauty and harmony in every context, respect for the environment and a balanced use of natural resources, resilience, democracy, and continuity with past traditions and cultural heritage. Unfortunately, however, the concept of sustainability is often wrongly applied, even in many so-called sustainable architectures. From the analysis of some projects emerges the unsuspecting unsustainability of sustainable architecture (Section 3.2.) which reveals a lack of memory and the supremacy of a self-serving technology [21] to the detriment of real human needs. This phenomenon is partly due to what is known as the greenwashing communication strategy, now becoming mainstream also in the sector of architecture [22,23], an approach that focuses on some aspects but overlooks others thus failing to see the interrelated nature of the many facets of the problem. Another aspect of this phenomenon relates to modernity and the blind faith in current techniques while discarding traditional solutions considered obsolete or because they have been forgotten. Memory is very important to bridge the cultural gaps with the past and start new relationships between the different components of the environment and man that have for some time been disregarded. In Section 3.3. I will propose an ecology of architecture which, through its various dimensions, enables a relational vision of both architecture and man, for a broader and more comprehensive conceptualization of the idea of sustainability [24]. Memory indeed, as the material of the project, has the capability of establishing relationships. Memory is relational, as it is by definition, ecology [25]. Moreover, forms, natural or artificial as representations of memory favor a deeper understanding of reality and awareness of the impact of our actions on the world [26]. And both reality and nature are full of shapes that retain or store memories through which we can learn how to live in a sustainable way. Finally, I will try to demonstrate how mnemonic processes are temporal and spatial agents capable of building bridges across generations. These temporal and spatial agents materialize through the development of spaces of enhanced habitability, in Heideggerian terms "dwelling spaces", where thoughtful consideration is given not only to the dweller but also to the dwelling place $[27,28]$. The limits of using memory as the material of the project will also be investigated to emphasize the difficulties involved in perfecting a 
universal solution or a deterministic method capable of effectively addressing the issue of sustainability. Nevertheless, the nexus between memory and sustainability offers the possibility for a redefinition of the concept of memory for future epistemological developments and related design practices.

\section{Objectives and Methods}

The objectives of the proposed considerations draw attention to the important role memory can play in finding solutions to the problem of sustainability. The re-organization of the theoretical framework of current sustainability paradigms aims at identifying in such paradigms their connection with memory. The reference to memory in the analyzed paradigms would demonstrate its significant role in their definition. Instead, the investigation on the practical value of memory in the project of sustainability aims at verifying, through the detailed analysis of some purported sustainable projects, the real effectiveness of their architectonic solutions. The objective, in this case, is to show that lack of knowledge, which, in turn, is also lack of memory with regard to technologies of the past that are still usable, or lack of memory in terms of multidimensionality of the project, translates into weak or even completely ineffective sustainability solutions. Finally, research and the comparison of case studies in which memory is used as the material of the project fulfills the need to find examples that can be used for workable solutions to be developed and implemented. The final objective is to share these considerations and examples with the scholar and the reader for a better awareness with respect to the necessity to use memory as an instrument of the project of sustainability. This is because it is clear that though memory alone would not be enough to solve the complex problem of sustainability this, in turn, cannot be solved without memory.

The methodology to verify the initial hypothesis, namely, the importance of memory in finding solutions for sustainability, reaches the set objectives as follows: a) through the redefinition of the theoretical framework of current sustainability paradigms; $b$ ) through the precise verification of the data relative to energy-saving measures, repeatable solutions, costs of the project and the efficiency of the implemented technologies in particular through the assessment of some of the most acclaimed projects in terms of sustainability; c) through the comparison of case studies which have used memory as the material of the project; $\mathrm{d}$ ) by identifying the limits of memory in the project of sustainability.

The theoretical framework of sustainability paradigms has been examined in depth in scientific literature, in terms of both the importance of memory and sustainability and their interconnections. The literature supporting the theoretical framework of the present article draws on the sector's specialist magazines and is validated by scholars-cited in the text and reported in the bibliography - whose credibility is universally acknowledged.

Data relative to projects of sustainable architecture discussed in the sub-section Unsuspecting unsustainability of sustainable architecture has been collected through both literature and information by the same firms and practices who have designed and developed said projects. In this case, the methodology is prompted by doubt rather than skepticism in relation to the acquisition of knowledge and in-depth analysis. To verify the sustainability of the projects discussed in the present article the collected data relative to costs, energy consumption, and choice of materials were analyzed and compared with their stated performances. In particular, for the case study of Mario Cucinella's Casa $100 \mathrm{~K}$, the energy requirements of the project were calculated using software for dynamic simulation of buildings, and the data were compared with the systems available on the market when the project was designed. The cost and energy performance of the machines and systems used for the project were verified through a market survey, again with reference to the data available at the time when the project was designed. When such data were unavailable or incomplete to verify the data featuring in literature, telephone interviews with a sample of five local construction companies furnished the relevant information on average local construction costs. The object of the survey was withheld from the interviewees to avoid biased responses.

The comparison of the chosen case studies, where memory was used as the material of the project, was carried out through a phenomenological approach to assess the solutions offered in literature as 
a work in progress. The different fields of application of a design method based on memory means a complex process of comparisons and synthesis of the adopted systems. This complexity, however, confirms the multidimensionality of the problem of sustainability which paves the way for a new definition of the concept of memory applied to sustainability.

\section{Results}

\subsection{Paradigms of Sustainability and Memory}

In the first definition of sustainable development that features in the "Our Common Future" report by the Brundtland Commission (1987), though not explicitly stated, there is a reference to memory. The relationships between each generation and future ones are, in fact, based on memory, as we must remember that after us many others will use the planet's resources and that these are not endless. In its most recent definition of sustainable development, made more comprehensive by United Nations Educational, Scientific and Cultural Organization (UNESCO) in 2001, the concept of safeguarding cultural diversity is introduced, as one of the pillars of sustainability together with ecology, equity, and economy. In this extended definition of sustainability, memory though not specifically mentioned, plays a critical role in sustainable development. The reason for this is because the introduction of culture and the acknowledgment of cultural diversity implies the following dual mnemonic work: first, the construction of community culture which, without memory processes-recollections or oblivions-could hardly be kept alive; and, secondly, the acknowledgment and respect of diversity. Indeed, the creation of the cultural heritage of any community, involves an incessant work on collective memory construction, a responsibility that each generation then hands down to the next. The Latin origin of the word "patrimony," made up of the nouns "pater" and "munus," that is, "the obligation of the father," stresses the responsibility each generation has toward the next ones: the future is thus built on the memory of the past [29]. Memory is, therefore, the relationship between past and present, but also between present and present, in terms of memory construction by contemporaries within the same community. Memory is content and container at the same time. A content consisting of memories, actions, feelings, impressions, events, histories, etc., and a container of signs, traces, stratifications, vestiges, cumulations, and overlays of things. This is why memory is multidimensional and a ubiquitous element of learning and the foundation of knowledge. Sustainability, as it has been defined, has the same characteristics of memory, and, as I will try to argue, is nourished by it and profits from it.

The signals we keep receiving from the ecosystem unequivocally tell us that a sustainable approach to human development cannot be put off anymore. For instance, our planet manifests its intolerance to human activities through climate change. Statements in line with this warning about climate change are increasing in number and are met with three types of response: absolute deniers, deniers, and merchants of doom.

Absolute deniers do not believe climate change is a reality. It is the case for instance, of US President Donald J. Trump [30], though it seems he has recently started to acknowledge the problem but blaming other countries for it, such as China, India, and Russia [31] and believing it concerns extreme weather conditions more than a generalized climate change.

Deniers, on the other hand, claim there is no correlation between human mismanagement of the ecosystem and the current climate change, arguing the phenomenon is due to natural causes and the sun. This is the position of Antonio Zichichi and the numerous scientists who agree with him saying that the impact of humans on the global climate would amount to no more than $5 \%$, whereas the sun would be responsible for the remaining $95 \%$. In addition, Zichichi claims there is no mathematical theory capable of representing and controlling the complexities of climate-related phenomena [32] and that pollution and climate change are unrelated [33].

Merchants of doom believe the problem of climate change is attributable to the ecological footprint: pollution, greenhouse gas emissions, over-exploitation of natural resources without taking into account the ecosystem's recovery times, societies highly dependent on technology, etc. They believe 
we are dangerously running out of time to figure out ways to reverse this trend, in other words, the worst is not in the distant future but is already here [34]. These three positions are now ideologically polarized, which, according to Slavoj Žižek, are becoming like new religions [35]. Further proof that the ideology of ecology is turning into a religion is the growing involvement of traditional religions in the ecology and sustainability debate [36]. The position of Pope Francis, however, is different from the three above, drawing the attention on a reality whose problems stem also from the lack of memory and therefore attention.

Memory seems to be missing since the beginning, as we have forgotten that, as written by pope Francis in the encyclical Laudato si' our own body is made from the elements of our planet, the same elements we find in the food we eat and the water we drink [36]. Forgetful are also technology and finance when they fail to see the complex interrelationship between mankind and the environment or when, to solve a problem, they end up creating more problems [36]. Philosopher Emanuele Severino expresses the same concept saying that "the world's scientific and technological complex have replaced their purpose with the never-ending capability to produce more purposes" [21]. In other words, technology has lost its "raison d'être" by creating new needs to further and strengthen the power of tech corporations. Furthermore, it seems that technology and industrial production have forgotten how natural processes work, where no waste is produced and everything is recycled [36]. Paradoxically, however, technology and industry use memory for their marketing policy known as planned obsolescence, even in the case of pro-sustainability products. In this case, memory comes into play in terms of program design. The machines, devices, and equipment we use have their in-built memories designed to stop working properly and eventually break down to force consumers to purchase new products. Planned obsolescence, therefore, furthers consumerism. The question we should ask ourselves is the following: in which ways could the current technocratic paradigm develop an interest in memory for a more sustainable and integrated approach?

First of all, it is important to say that technology is not the only place where to look for solutions as it cannot solve the problem without the conscious and goal-directed action by humans. Solutions are to be found at the source, that is, through a re-definition of the role of technology in the context of a radical change of the paradigm of modern consumerism. Literature offers several options with regard to paradigm changes in an attempt to imagine solutions for our present and future society. Many of these new paradigms are based on the idea of memory and the relational processes it gives rise to.

The utopian degrowth theory by Serge Latouche [37] proposed a radical paradigm change, which, like any utopia, was necessary to provoke within this debate also conflicting positions $[38,39]$ but useful to stress the urgency of what is at stake in relation to the environment. In Latouche's model of society based on the virtuous circle of the " $8 \mathrm{Rs"} \mathrm{(Re-evaluation,} \mathrm{Re-conceptualization,} \mathrm{Renovation,}$ Redistribution, Relocalization, Reduction, Re-utilization, Recycling) every action is linked to memory. The " 8 Rs" can, in fact, be summed up in just one " $R$ " standing for the action of Remembering, without which none of the others would be possible. Incidentally, Latouche chooses words that feature the prefix "re" (from the apocope of the Latin word "retro", used also in other languages such as Spanish and French) through which we indicate iterative processes. Actions, however, can be iterated only if they have been performed at least once. Iteration, therefore, is possible only thanks to the action of memory. Latouche, however, warns not to keep repeating things with a reactionary attitude, an approach typical of those who wish to uncritically return to the past. The innovation of any process, in fact, proceeds as memory does, that is, drawing on both recalling information and oblivion, so that nothing will ever be repeated in the same way, but adapting and innovating things according to specific situations.

Zygmunt Bauman, on the other hand, does not indicate a model to follow but agrees on the necessary role played by a utopian approach. He claims that in this liquid world, characterized by the speed things are made obsolete, also culture appears to be a "disengagement culture, of discontinuity and forgetfulness" [40]. In this new situation though, according to Bauman, turning to memory to address today's uncertainties is a viable option but it has to be carefully evaluated as it isn't always 
possible to replicate "tout court" what in the past proved to be successful. Past good results, therefore, should not put our minds at ease, also because "to soon and completely forget old information and past habits can be more important for future successes than memorizing past solutions and strategizing drawing on what we have already learned" [41]. Memory, in this case, has to forget to make room for innovation and new solutions.

The paradigm of a circular economy, as opposed to the linear one [42], is another possible solution. It is rooted in the memory of the ecosystems themselves which work circularly and are self-sustaining, not producing useless waste. Nevertheless, it seems that not even this is going to be enough unless we significantly change our lifestyle by giving up consumerism and embracing moderation and, last but not least, by replacing fossil fuels with renewable sources of energy [43].

Biophilic designing, on the other hand, aims at improving the sustainability of urban life through green spaces [44]. Citizens of the biophilic city play an active role in taking care of the natural environment through which they learn both about nature and how to respect it. The biophilic city, not to be confused with the garden city, is, according to its advocates, more resilient to climate change and natural calamities. However, resilience alone as an objective is not enough to be protected against natural disasters which, at least those that are directly or indirectly caused by man, should be prevented. Memories regarding the havoc some catastrophes can wreak on humans and the environment are critical in terms of resilience and awareness. Memory helps humans develop resilience and to decrease risks. Forgetting is sometimes indispensable to start reconstruction right after the traumatic events. The combination of collective and individual memories though they may appear as if taking divergent routes complete each other: individual memory removes the trauma to keep going after a shock, while collective memory should help people remember the events to lay the foundations of more innovative prevention strategies and culture. In line with this, Maurice Halbwachs writes: "it's the repercussions, not the actual events that will linger in the memory of the people who suffer them, and this takes place the moment the victims are hit by the calamity" [14]. The heritage of collective memory is institutionalized and turns memories into actual physical spaces and places meant to keep those events indefinitely alive. Indeed, the relationship between space and time is built on memory.

The importance of institutional memory, the political one, in particular, is stressed by scholars like Gianfranco Marrone who remind us that "nature does not exist in a sort of vacuum, but is part of the culture, sometimes as one of its constituents, sometimes as a separate element" [45]. The paradigm of "multinaturalism" arising from this approach acknowledges that every culture produces a different nature, hence the latter is not univocal and definitive but changing and evolving. The cultural requirements of sustainability are a central issue as they involve the system of values through which reality is represented. This system includes nature as a value rather than simply as an "external and mute" element. Multinaturalism, the loss of which would be detrimental to sustainability itself leads, according to Marrone, to happiness [45]. The multicultural/multinatural proportion in terms of relationships and memory could also lead to the resolution of the anthropocentrism versus biocentrism dichotomy, which, when taken into account separately, can determine very negative outcomes.

The set of presented paradigms, as I have tried to show, is made up of an ever-growing number of complex solutions that try to address the multidimensional nature of sustainability. Every dimension, in fact, offers signs through which it should be possible to retrace the actions that produced a given calamity in the natural environment, severed relationships or compromised resources. These signs, their shape and geometry, are real forms of memory [26] which, if analyzed, can yield a plethora of information useful for prevention policies and strengthen resilience. Their shape can indicate what produced them. Their nature and conditions can tell us when they were produced. Further, they may contain traces of the materials that formed them. It is no coincidence that scientists have identified the presence of water on Mars, studying the furrows on the surface of the red planet and comparing them with Earth's [46]: geometric memory of the passage of liquid. 
Other types of geometric memories are cities and architectures that reflect the spirit of the historical period they were built and were most human activities having an impact on the environment have concentrated throughout history. Cities and buildings are today blamed for being the source of the planet's greatest resources and energy consumption at the expense of the environment. Architecture, as well as cities, have become complex energy-consuming machines with an ever-growing demand for new land. Their ecological footprint keeps increasing, constituting a major concern for analysts and sustainability experts. For these reasons, design disciplines are working to lessen the impact of architecture and cities on the environment. However, theoretical speculation and constructions are still far from the goal of significantly reducing the ecological footprint. Furthermore, sometimes while looking for the best pro-sustainability technology planners keep proposing solutions that can hardly be defined as sustainable.

\subsection{The Unsuspecting Unsustainability of Sustainable Architecture}

Has architecture always been unsustainable? This is the question I ask as an incipit for the following considerations. Or, perhaps, we should ask: when did architecture become unsustainable? The history of architecture answers the first question through the thousands of years of construction methods and architectures compatible with the environment. With regard to the second question, on the other hand, I would agree with Andri Gerber, who said that architecture becomes unsustainable with the introduction of the modern concept of consumerism [47]. This happens when architecture becomes a consumer good turning its artistic and social value into an economic and functional one. To what extent then is this problem linked to modernity? What is modernity? Modernity has been a beautiful chimera that, according to scholars such as Bruno Latour, it's an invention we should disinvent [48], whereas other thinkers such as Zygmunt Bauman believe modernity is "a universal condition of mankind" [40] which is impossible not to deal with. The myths of modernity are a novelty, design, technological and scientific development, and information [40]. Man has shown a blind faith in these myths, seduced by the idea of endless innovations and progress, the promise of a better life and the resolution of all problems, the delusional idea that modernity means being better individuals, the promises of free and democratic states, the certainties of experimental knowledge, the speed of modern traveling and communications, the unprecedented and widespread availability of information, the new and never seen before representations of reality, the construction of more effective tools in every field, the awareness of being capable of dominating nature, the charm of functional aesthetics, the rationalization of vital habitats, the heroic stand of man on the stage of his anthropocentrism and so forth. Modernity has therefore been built on these new myths rejecting the old, antiquated ones since these started being considered ineffective, obsolete and too much rooted in traditional concepts and craftsmanship, empirical knowledge, alchemies, medieval-style trade associations, and construction methods. Rejected too were also adobe villages, cities perched on mountaintops, kasbahs, architectures without architects [49,50], spontaneous technologies, and natural materials.

David Harvey associates modernity with capitalism and its evolution [51]. All these developments have taken place alongside the processes that have led up to our consumerism-based Western culture and the progressive distancing of society from nature and man from the cosmos. A process that Marcel Gauchet defines as the "disillusionment of the world" [52] through which the modern man has marked their experience as something different from the primitive man, not in terms of gradual, sequential evolution but in terms of being capable of exercising their freedom to choose: the modern man feels he or she can define their world and take responsibility for their self-determination. The modern man, therefore, detaches himself from the cosmos and nature to dominate them, rejecting the primitive sacredness of these worlds seen as a hindrance to their freedom, to invest in the future, on politics, and knowledge to pursue material efficiency and performance for their own sake. It is nature itself that reminds mankind that not only their ties with it cannot be completely severed but they have to continue establishing relationships with it. The chimera that man is capable of dominating nature at will, reckoning without their host (nature), is the greatest deception of the modern age. A deception 
that has been so pervasive as to have deeply affected every aspect of the human condition starting from the religious dimension [53]. In architecture, according to Bauman, the cause of this deception lies in the rejection of the world as it is, a characteristic typical of modernity. [40]. As a result, the project of modernity is changing for change's sake, no matter the outcomes in terms of unsustainability. Another characteristic of modernity associated with change is the speed through which all this takes place. These two conditions have led Franco Cassano to the conclusion that "modernizing is tiring" [54] and that the philosophy of the endless "becoming" demanded by modernity emphasizes death above all else because everything is very soon made obsolete by the new products. The philosophy of newness at any cost is starting to deal with sustainability, especially in architecture. It's imperative to reconsider the impact of architecture on the natural environment, a problem which is usually addressed drawing on statistical data to find suitable solutions and above all relying on high-performance technology. Scholars such as Mirko Zardini see in this one of the main problems because they think that in light of this "green functionalism" it's time now to redefine technology's role in the field of sustainability and twenty-first-century architectonic culture [22]. As stated by Greber, this is the "Al Gore scenario," that is, fixing the ecology problem and therefore also architecture's, by merely complying with norms and regulations. Yet, compliance with technical standards is no guarantee of "good" architecture. In fact, "good" implicitly in ethical terms and consequently also in aesthetic terms (green architecture looks good), as the architecture respects the environment. This is, for architecture, a fatal conclusion which again leads it into the arms of developers who not only will continue to be able to argue the advantages of their houses and buildings in terms of lower costs and precise delivery times but will now also claim ecological, and thus ethic and aesthetic benchmarks" [47]. If aesthetical and ethical values were to be reduced to globalized technical parameters to guarantee a sustainable architecture, what would the consequences be for future generations? We should not forget that one of the values of architecture is linked with memory [55] and that, as advanced by pope Francis, "if architecture reflects the spirit of an age, our megastructures and drab apartment blocks express the spirit of globalized technology, where a flood of new products coexists with a tedious monotony" [36].

This is only partly true because in the world of design there is a growing awareness regarding the environment and that this multidimensional problem calls for a multidimensional response. However, data suggest that in Italy for instance, the construction sector in the first decade of this century was responsible for $40 \%$ of the global energy consumption and $51 \%$ of the total $\mathrm{CO}_{2}$ emissions in that country [56].

The first responses to the problem of architecture's ecological footprint were usually imperfect, and sometimes not quite sustainable at all. Below, for instance, are reported some cases of sustainable architectures that have proved to be unsuspectingly unsustainable [57], representing an outcome of the so-called "sustainability narrative" [58] which is closely related to the concept of greenwashing.

The Sino-Italian Ecological and Energy-Efficient Building (SIEEB) (Figure 1a) is the Sino-Italian academic training and research center for environmental protection and energy conservation designed by Mario Cucinella, where high technology together with rigorous building exposure and morphology analysis to address environmental issues are their established modus operandi. The complex, which was built in 2006 on the campus of Tsinghua University (Beijing), has the following objectives: save power, environmental resources, and construction materials; reduce the impact on the environment both during and after the building phase; use domotics for its operation and maintenance; improve indoor air quality; use lasting and low environmental impact materials; recycle and re-use water. To accomplish all this, the building was designed to reproduce the natural process of photosynthesis, turning sunlight into power. The building features a courtyard on one of its sides to best exploit sunlight and optimize natural lighting for as long as possible. Artificial lighting is operated automatically. SIEEB is a wholly shielding glass building featuring also a double-skin façade system where sunlight is more extreme. A Heating, Ventilation, and Air Conditioning (HVAC) system minimizes power consumption. More than $1000 \mathrm{~m}^{2}$ solar panels meet the building's power demands while a Combined Cooling, Heating and Power (CCHP) trigeneration system covers other energy necessities. Despite the 
state-of-the-art technological solutions, after 5 years only SIEEB started showing some problems [59]. The high technology of its solutions has normative and functional limits. The CCHP system for instance, has never worked because it fails to meet the Chinese safety standards. Only 180 out of the 500 solar panels are working, producing $1 \%-3 \%$ of the required annual power instead of supplying the entire amount of energy necessary for the lighting of the building. The maintenance of the building, given its materials, is very costly. Further, a change of designated use from offices to laboratories provided for at the design stage is the origin of unpleasant odors despite the fact that the fume disposal system had been upgraded. Finally, the staff questions the choice of replacing traditional switches with automatic ones they think they are unreliable and less user-friendly [59]. SIEEB, therefore, shows several unsustainability issues from the economic, social, cultural, and functional points of view.

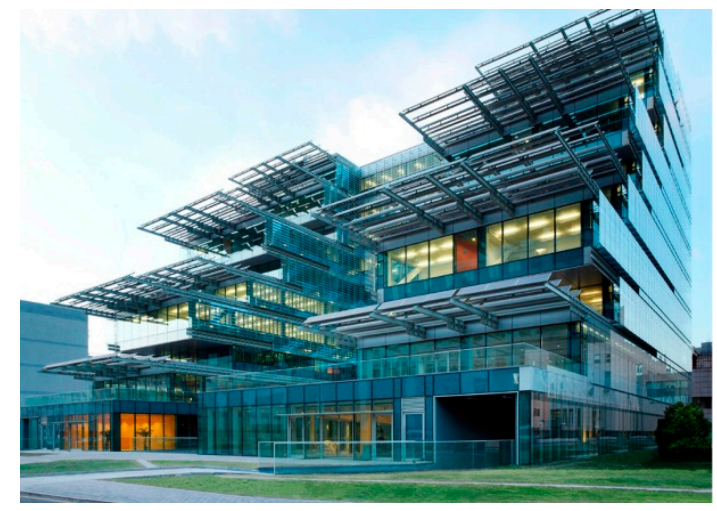

(a)

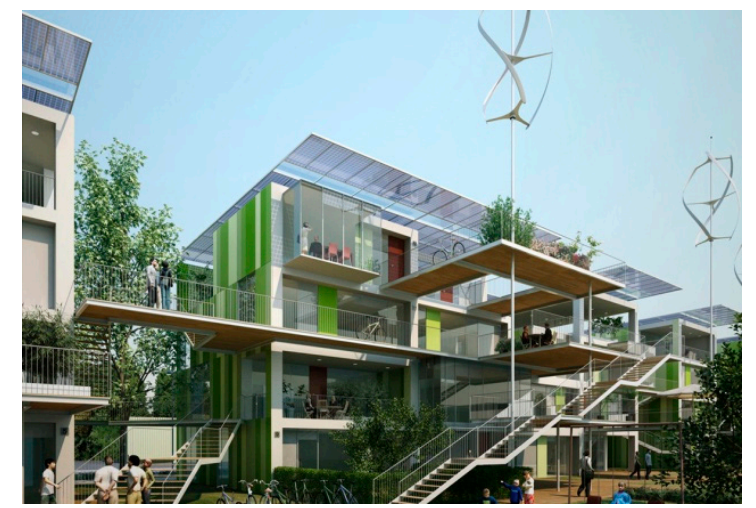

(b)

Figure 1. SIEEB, (a) Casa 100K; (b) projects by Mario Cucinella, Daniele Domenicali, Alessandro Di Gaetano/MCArchive.

The project for Casa 100K (Figure 1b), another work by Cucinella, is a never-completed 2007 patented project, which opened the season of sustainable residential architectures. With this project, Cucinella took on the challenge of designing a sustainable as well as affordable residential architecture. His idea was a designing strategy capable of elevating the architectonic value of a building's high-tech solutions for facilities and fittings by integrating these with the structure's architecture. The structure is prefabricated and it can accommodate different types of $100 \mathrm{~m}^{2}$, zero $\mathrm{CO}_{2}$ emission apartments, costing $€ 100,000.00$ each. The utilized passive and active devices for the building's design are the following: orientation of the houses so that the north and south faces have a clear view to favor natural ventilation; service areas on the north side of the houses while the sides on the south feature glass walls to exploit solar gain; on the south sides glass walls are shielded by colored brise-soleil, eaves, balconies, and external staircases; a horizontal pergola solar panels system of approximately $30 \mathrm{~m}^{2}$ per apartment; a roof solar thermal system; reversible heat pumps paired with geothermal or groundwater probes powered by the electricity produced by the solar panel system; underfloor heating system and air handler with heat recovery; an integrative system consisting of a biomass boiler powered by green areas maintenance organic waste; a system to recycle and reutilize water; a micro-aeolic system.

In this case, the economic data and energetic values found in literature and interviews by Cucinella himself were verified [60]. Through dynamic simulations analysis, it was calculated that the building needs a total of $41 \mathrm{kWhe} / \mathrm{m}^{2}, 21 \mathrm{kWhe} / \mathrm{m}^{2}$ of which for the heat pump, and $20 \mathrm{kWhe} / \mathrm{m}^{2}$ for ordinary power consumption (lighting, home appliances, etc.).

Verification calculations of the solar panel system yield were carried out using the climate data of Settimo Torinese [61], where the prototype of "Casa 100K" was to be built, though eventually, it was not, whose coordinates are the following: $45^{\circ} 8^{\prime} 37^{\prime \prime} \mathrm{N}, 7^{\circ} 44^{\prime} 59^{\prime \prime}$ E. According to the data obtained it would have been more profitable to install the panels with an inclination of $45^{\circ}$ relative to the horizontal plane, but due to architectural choices they were placed horizontally. 
Calculations were carried out using a monocrystalline silica solar panel with the following characteristics: standard conditions peak power: $250 \mathrm{~W}$; surface: $1.62 \mathrm{~m}^{2}$; standard conditions efficiency: $15.2 \%$; nominal operating temperature of the cells: $47.5^{\circ} \mathrm{C}$; temperature coefficient: $-0.00491 / \mathrm{C}^{\circ}$.

The calculation of the electric production was determined using also the data relative to both the panel's ventilation (considered not ventilated because it was installed horizontally) and the presence of the glass.

The total number of panels per apartment was calculated which corresponds to the total surface of each apartment divided by the surface of a single panel thus: $30 \mathrm{~m}^{2} / 1.64 \mathrm{~m}^{2}=18.3$ panels.

Based on these data, it was estimated that the system could produce $43 \mathrm{kWhe} / \mathrm{m}^{2}$, which is enough to meet the power necessities of the house. It was verified however that placing the solar panels at $45^{\circ}$ rather than horizontally, the cost of four panels could have been saved, that is, the number of panels in excess with respect to the estimated necessity.

Having verified that the building's energy production coincides with the designer's statement I verified the Casa $100 \mathrm{~K}$ 's economic sustainability. The crucial aspect is, according to Cucinella, its economic sustainability [60]. According to an estimate of standard building costs, Casa 100K should cost $1000.00 € / \mathrm{m}^{2}$ (Table 1), that is, $€ 100,000.00$ for $100 \mathrm{~m}^{2}$, turnkey condition, while in the 2007 Italian real estate market, a property of the same size cost an average of $€ 263,000.00[60,62]$.

Table 1. Standard construction cost for Casa 100K by Mario Cucinella [60].

\begin{tabular}{|c|c|c|}
\hline \multicolumn{3}{|c|}{$\begin{array}{l}\text { Standard Construction Costs } € / \mathrm{m}^{2} \\
\text { (Impact on the Total) }\end{array}$} \\
\hline Foundation structures & $5.46 \%$ & 48.93 \\
\hline Load-bearing structures & $13.19 \%$ & 119.99 \\
\hline Foundations and flooring & $6.05 \%$ & 54.22 \\
\hline False ceiling and roof & $4.39 \%$ & 39.34 \\
\hline Staircases and external balconies & $6.35 \%$ & 56.90 \\
\hline Windows and door windows & $11.03 \%$ & 98.84 \\
\hline Walls and external walls coating & $10.39 \%$ & 93.11 \\
\hline Prefabricated bathroom and kitchen units & $6.31 \%$ & 56.55 \\
\hline Technological building & $1.68 \%$ & 15.05 \\
\hline Installations & $34.95 \%$ & 313.20 \\
\hline \multirow{3}{*}{\multicolumn{2}{|c|}{$\begin{array}{l}\text { Cost of the work } \\
\text { Technical expenses } \\
\text { Total costs/house }\end{array}$}} & 896.13 \\
\hline & & 103.87 \\
\hline & & $1000 € / \mathrm{m}^{2}$ \\
\hline
\end{tabular}

An early verification was carried out to estimate the costs of the building services (heat, power, $\mathrm{A} / \mathrm{C}$, water) only, using the 2007 data, both for the characteristics of each component and their prices. A $30 \mathrm{~m}^{2}$ photovoltaic system was estimated to cost around $€ 10,000.00$, complete with labor, materials, and installation costs. The thermal solar system with two panels and a 150-liter boiler (calculated for a family of four) must have cost $€ 1420.00$. The micro-aeolic in carbon fiber and epoxy resin as indicated by the designer must have cost $€ 40,000.00$ per column. For the radiant floor heating system, considering the price of $€ 60 / \mathrm{m}^{2}$, the lowest of the market, it must have cost $€ 6000$ to cover $100 \mathrm{~m}^{2}$, complete with labor, materials, and installation costs. The costs of both the geothermal heat pump (GHP) and the biomass boiler were also estimated, but without details about their size, I assumed that, given the autonomy of the single housing units, the installed systems' characteristics were chosen to meet the needs of families of four. The GHP must have cost around $€ 20,000.00$, while the cost of the reverse flame biomass boiler about $€ 4000.00$, in both cases excluding their installation.

Taking into account possible tax credit incentives available in 2007 in Italy, the only possible one was the "Conto Energia" for the installation of systems for the production of power from renewable sources. It was then calculated the tax credit available which provided for a reimbursement of $€ 0.445 / \mathrm{kWh}$ 
produced which, multiplied by the $4100 \mathrm{kWh}$ of the total power production, meant a reduction of $€ 1824.50$ of the costs of installation of the solar panel system, obtaining a total cost of 10,000 - 1824.50 $=€ 8175.50$. The micro-aeolic tax credit, on the other hand, must have been less significant with respect to the system's entire cost. However, considering the subdivision of the costs of the four apartments of the block, the price for each housing unit must have been very close to the photovoltaic one. Hence, the total estimated cost of the services (heat, power, $\mathrm{A} / \mathrm{C}$, water) for each housing unit is around $€ 40,000.00$.

Not having the project's details, the building companies of Settimo Torinese were asked-via telephone interviews-the average construction costs of buildings of the same type. Survey data show that according to the companies interviewed $(100 \%$ of the total) the average cost to build a single housing unit with the same characteristics of "Casa $100 \mathrm{~K}$ " is about $€ 1600.00$ to $1800.00 / \mathrm{m}^{2}$ (the costs for the company) and $€ 2000.00$ to $2200.00 / \mathrm{m}^{2}$ (costs for the buyer). The conclusion, therefore, is that Cucinella's "Casa $100 \mathrm{~K}$ " is not an economically sustainable option due to its very expensive technology.

In other cases, unsustainability depends on the impossibility to reproduce some models on a large scale. Follows that finding circumscribed solutions to a global problem, however commendable, is not the way to sustainable architecture. It's the case of two very much advertised and quoted sustainable architectures of the last years: Stefano Boeri's "Bosco Verticale" completed in 2014 and the Masdar City by Foster \& Partners completed in 2015. The impossibility to repeat Boeri's model on a large scale is due to the very expensive interventions, making them unsustainable economically and socially. The "Bosco Verticale" in fact cost 40 million euro and its apartments are far from accessible to the average buyer. What took place here is the exact opposite of what happened to Cucinella's "Casa $100 \mathrm{~K}^{\prime \prime}$. Similarly, Masdar City is a city built in the desert whose construction costs included reclaiming the land and the development and maintenance of green areas. The high costs of the interventions mean that potential buyers are selected according to their income, thus forming enclaves which, contrary to the principles of sustainability, sever relationships, without offering pro-environment working solutions. Further, as postulated by Vincenzo Cribari "we would again have to deal with styles, though in an updated fashion, of living conditions in which the predominant technological and technical vision risks being reduced to yet another market invention, rather than being the model of a new and autonomous urban organism." [63]. In addition, wrapping a skyscraper with trees or vegetation has some critics warn that this solution is more a greenwashing strategy than a way to improve the environment. This is because integrating many trees in a tall building calls for the inevitable reinforcement of the structure which, in turn, means more materials and a bigger impact on the environment, not to mention the positioning, maintenance, and irrigation costs [64].

This takes place when the ends are replaced with the means and when modernity forgets tradition. Keeping tradition alive does not mean being reactionary or living in the past. Tradition is memory and it means handing down from generation to generation something tangible or intangible. In origin, the word "tradition" meant also "betrayal" which is also oblivion. Tradition, therefore, has to be seen not only as an affirmation of the past but also as a learning tool whose value lies in its capability to improve the quality of living, implementing more effective and sustainable solutions than current ones. The work of memory—a continuous oscillation of memories and forgotten experiences—can be aligned with the meaning of tradition and interpreted most vitally and spontaneously, just like it was in the past. Not everything is handed down from generation to generation, a lot is forgotten because new products, ideas, discoveries make things obsolete, but what is advantageous is kept.

\subsection{Memory as Material of the Project}

To rediscover traditions, including those that pertain to architecture and construction, it is necessary to turn to memory. The historical role of memory according to Le Goff, is to be at the service of the present and of the future [65]. Memory can also construct images devoid of meaning if used as a simple representation of the past. In this case, it is only oblivion, the other face of memory, which can also be the solution: forget to move on. Indeed, among the many ways to turn to tradition, two antagonistic approaches, produce - paradoxically—-the same results in terms of architectonic images, though not 
offering the same solutions for the environment: the first, drawing on the technical knowledge and expertise of the past and in continuity with it, reproduces and updates the same processes to obtain better architectural performances and quality of life; the second on the other hand proposes as if by inertia, only a superficial image of the past. An example of the latter approach is the building of new "dammusi" (plural of "dammuso"), Pantelleria's typical houses, today built using reinforced concrete for the structure and, for the façades, perforated bricks clad in lava stone. This is meant to "respect" the surrounding landscape but being these new "dammusi" heated and cooled with heat pumps, which are absent in the original ones, fail to be sustainable. Indeed, through the study of traditional architectures, including those without architects, Bernard Rudofsky learns that "many audacious "primitive" solutions anticipate our cumbersome technology; that many a feature invented in recent years is sold hat in vernacular architecture-prefabrication, standardization of building components, flexible and movable structures, and, more especially, floor-heating, air-conditioning, light control, even elevators" [49]. It may seem that nothing new has been invented with respect to the past and that modern technology has only borrowed from the ideas of the past modernizing them. Man has however forgotten where the solutions of today's problems originate. This oblivion is perhaps due to the contemporary man's progressive relying on modernity and technology for workable and sustainable solutions capable of meeting their needs.

A trend reversal could instead aim at using memory as the material of sustainability for knowledge acquisition and design. Our own body and skin are in fact memory loci, through which we perceive and imagine reality [66]. Memory is what surrounds us and its meanings depend on the perception we have of our environment, and it's thanks to this memory that we inhabit reality.

Memory associated with environmental issues is, in fact, a research topic that is involving scholars of different branches of learning. The Rachel Carson Center (RCC), an international interdisciplinary center for research and education in environmental, human, and social sciences, in 2009 had already started a research project named "Environment and Memory. Towards an Archeology of Environmentalism" [67]. Their research assumption is that environmental issues have always existed and have left with us traces and memories, both material and immaterial. The study of places of environmental memory offers a cross-section of the events and of the politics that have been implemented not to worsen the situation. This particular investigation has yielded a comprehensive understanding of the issues looking also to the pre-modern era, in particular to places of relevant environmental memory such as windmills and ancient agricultural traditions. Though the RCC research focuses more on the German situation, the choice of places to review also outside their territory is evidence of the impact global dimension events have on the collective memory. The investigation of memory in this context considers also how debates on environmental issues, conservation of nature, and the problem of climate change have evolved. The evolution of ideas and environmental policies can shape the environment and provide a more comprehensive understanding of the issue of sustainability. Every action on the environment leaves traces behind which "materialize" into memories that are not always actual places [68] which, if mapped together with the physical ones, can teach a lot with regard to the history of our behaviors [67]. Memory is thus materialized, turned into the substance we use for the project. Many are the fields of knowledge that draw on memory to tackle today's ecological emergencies also through the redefinition of the principles of multidimensionality of sustainability.

Turning to memory to advance the sustainability project involves also the production and consummation of food from the anthropological, historical, and archeological points of view [69]. Looking to the past in relation to the development of future strategies for agricultural and food safety means acknowledging the importance of the wealth of information regarding both the successes and the failures in these fields. It is thus possible to draw on this information to find solutions for today's problems and prevent future ones. Memory of agricultural and food production practices borrows from the landscape, the evolution of seeds, farm animals, cuisine, rural villages, language, narratives, etc. Integrating the value of all these traditions with the environmental memory [70] in the quest for 
sustainability is useful to avoid certain strategies that are bound to fail as they are not grounded on the understanding of any cultural and historical context.

Memory is a tool for the acquisition of knowledge and learning. Since infancy, the places of memory start outlining our mental maps and building reference systems on environmental factors that affect the child's perception [71]. This is the way to build the basis for a sustainability-conscious education. Today social networks too can be used to boost communities' "socio-ecological memory" as a means to reach as many people and communities as possible which can then benefit from the constitution of a network of shared memories [72].

Memory as a tool is also useful in fields of the sustainable project which have direct implications for the securing of the territory against floods, because "what is often missing in the sharing and exchange of know-how between experts and communities, is the role that memory plays in organizational and institutional narratives" [73]. Recalling disastrous events like floods enhances the territory's resilience as these events are cyclic and therefore more easily remembered. In particular, the emotions produced by events caused by water have a lasting impact on individual and collective memories [74].

A methodology that uses memory as the material and instrument for a project of sustainability is the one implemented in the case study of the former industrial complex of Piaggio in Finale Ligure, Italy [1]. Collective memory and symbolic meanings are here to the subject matter of social and cultural discourse, which, if taken into account at the decision-making stage, contribute to achieving multidimensional sustainability. Collective memory, in this case, acts within the institutional dimension, making up for the collectivity's insufficient representativeness. Collective memory is undoubtedly the custodian of the identity and culture of a community, the material through which a sustainable-conscious culture is built. In particular, in the case of interventions on existing cities, collective memory can also be the engine of sustainability [75]. Further, the concept itself of heritage, be it natural, artificial, or cultural is part and parcel of the collective memory of any society. One of the possible definitions of heritage is given by memory, that is to say, heritage is a selection and collection of narratives and stories from the past that speak to and enrich the present. The natural heritage associated with memory as envisaged by Françoise Choay, should be managed and protected just like the architectonic and cultural ones, calling for "competence" to "reclaim this memory of gestures and ancestral customs" [76]. This has taken place with the implementation of ancient building techniques which are today modernized and used in architecture, such as, for instance, the earthbag technique, which consists in bags filled up with a mix made up of raw soils, an example of which is Pilar Diez's "Las Cupolas" restaurant in Palencia [77].

The key role played by competence with regard to memory is due to the ambivalent nature of mnemonic processes: recollections and oblivion. Certainly, memory can be both a friend and a foe of our heritage. It is a foe when a particular type of oblivion prevails [29]. The work of memory in terms of oblivion and removal involves also harmful behaviors toward the environment resulting in the phenomenon known as non-ethical amnesia, a careless attitude that allows some to have no qualms trampling on ethical or moral values and keep enjoying a good standing in their communities [20]. Another way forgetting works in the live and active processes of memory is by removing only some types of information retaining others $[13,18]$. According to some scholars, this memory mechanism should be taken into account in the decision-making process regarding the heritage to head off the "crisis" stemming from the accumulation of things from the past [19]. This is possible due to the difference between memory and history $[14,15,17,67,78]$, but they are not mutually exclusive but complementary $[16,79]$. Nevertheless, forgetting involves also risks that should not be minimized, because the counterweight of the crisis occurring with an excess of accumulation deriving from the past [19] is total oblivion, ergo, the dissolution and death of the entire heritage [80]. Losing the past means losing the future, and that is why memory is an all-important asset for man and their relationship with the environment. However, the misuse of memory as the material of the project can lead to aberrations and distortions of reality. A memory-based on false myths, built on prejudices or misconceptions, can distort reality thus giving little or no contribution to history and society. This may 
depend on the post-modern use of memory which carries with it several limits that, in the past, was endorsed by both the political and design establishments. The betrayal of memory, in this case, takes place when, as written by Theodor Adorno: "... even the past is no longer safe from the present, whose remembrance of it consigns it a second time to oblivion" [81]. The limits of representing the past as "present ancient" are also highlighted by Gilles Deleuze: "the limits of this representation or reproduction are determined by the variable relations of resemblance and contiguity known as forms of association" [82]. In other cases, memory is instrumental in the construction of a deeper awareness and therefore knowledge of the heritage that has to be preserved and given new life through management strategies and actions based on a stronger perception of the heritage itself.

As time passes by, memory can work as an agent across each generation facilitating sustainability. Relationships between and across generations are mnemonic. They are manifest in the physical space in terms of heritage and nature in general. Both these concepts, heritage and nature, apparently antithetical, are cultural constructions thus having a twofold connection with memory: as custodian of traces and as an agent. The action of memory as a temporal and spatial agent between and across generations is an opportunity to be seized also in architectural designing. In particular, re-use strategies can be associated with memory as the first material to be re-used in the original project, the blueprint that is always present in memory. In re-use designing, we have always to deal with memory. Salvatore Settis explains why: "man's space (... ) is the reflection and memory of both history and society, or rather, the reflection and memory of the histories and societies that have modeled this space across time until now for the men and women of tomorrow" [80]. The re-use problem, therefore, is not limited to the object to be re-used and to intervention modalities but, even before any designing decision, it establishes relationships with time. The spaces of architecture and by extension cities are closely related to time. Architecture is both a representation and a petrifaction of time. The definition of architecture as solidified time gives an idea of the size of the role it has played and keeps playing in human society. Memory, on the other hand, is the potentiality waiting to be materialized in the project of sustainability. Materialized memory can, therefore, fulfill its purpose in the various relationships between the many dimensions of knowledge and sustainability.

All this, however, cannot be achieved unless a recipe or a universally valid theory capable of changing current paradigms is found. First of all, because memory-by itself-cannot resolve the problem of sustainability. Nevertheless, memory can help by informing pro-sustainability strategies thus charting the course for possible solutions. We know in fact that the best way to find a solution to a problem lies to a significant extent in the definition of the problem. Memory can be of great help in this context: for instance, remembering the origin of a problem means not only remedying the damage but also identifying the root of the problem. The difficulty in these cases lies in finding an agreement on the origin of the problems, the environmental one in particular, as shown by the current debate on the issue [31-34]. Secondly, for at least another two reasons which are also complementary: on the one hand, though the problem of sustainability is a global one, literature shows that solutions must be found at the local level [1,68-75]; on the other hand, it is memory itself that determines the complex nature of sustainability. The advantage of using memory as the material of the project could, however, lie in the universal character of mnemonic processes [13-18]. Indeed, while memories, both individual and collective can be differentiated and can be more or less truthful, the mnemonic process could constitute the first answer to a global solution to the problem. Research should, therefore, focus on the modalities of mnemonic processes rather than on single memories that can be distorted and manipulated. A second line of research should be carried out to define new concepts, starting from the concept of memory in relation to sustainability as we have seen in different paradigms, as to set up a system of axioms and definitions with a much wider range of applications [83]. Just because of this last reflection together with all other considerations, the question remains an open one lending itself to further investigation: which new behavioral and procedural paradigm could be defined starting from new definitions of sustainability and memory? The answer, given the multidimensional nature of 
the subject, cannot come from one branch of learning only, but has to be transdisciplinary and collective, and it should be based on the awareness raised by this scientific work.

\section{Conclusions}

I have tried to argue that memory and sustainability are closely related and can be used as instruments. Memory at the service of sustainability can meet the demands of multidimensionality which is more relevant than ever when it comes to choosing strategies for the future. Certainly, memory can guarantee a higher awareness in relation to the actions to undertake, especially when it is necessary to look to the past to project oneself or one's ideas into the future. The reflections I have proposed in the present article are based on the fact that memory is part and parcel of the human being and that the environment is pervaded with memories. Nature, culture, heritage, architecture, cities, the territory, the landscape, and the environment are places of memory whose existence is built on their reciprocity. The possibility therefore of an ecological memory to prevent polarizing and coeval phenomena such as ultra-denialism and ecological merchants of doom from hindering free and authentic knowledge of the issues concerning the environment, depends on acknowledging the pivotal role played by an ecology of memory. This, as we have seen, emphasizes the importance of the specific elements of the past that continue in the present. The same definitions of sustainable development that have come in succession, from the first to the most recent one, have all hinged on memory. Likewise, the paradigms of sustainability find in memory the basis for their materialization.

The proof that current sustainability paradigms are based on the concept of memory is given by the definition itself of the different meanings attached to sustainability. We have seen it in Latouche's 8Rs whose iteration means the repetition of instances of memory; or the "condition of liquidity" by Bauman who, in the lack of memory, identifies both the causes and the solutions to the current situation; or the circular economy paradigm whose foundations lie in the memory of the laws of the ecosystem. Each of these paradigms, however, is incomplete and therefore ineffective because they fail to take into account the multidimensional nature of sustainability.

The downside of the ever-increasing awareness about the environment is the emergence of the greenwashing phenomenon and other attempts to tackle ecological issues resorting to not very sustainable technologies. Research seems to confirm that the myth of modernity and its economic and technological offshoots are the causes of today's environmental-related problems. Consumerism, the main outgrowth of this myth has transformed our system of values into consumer goods, whereas technocracy has replaced the instruments with the ends. So far, the analysis of sustainable architectures reveal-again-the inadequacy of the solutions proposed as they fail to consistently meet the requirements of sustainability on most of its dimensions. The scientific analysis of the data has shown that projects such as SIEEB, Mario Cucinella's Casa100K, Stefano Boeri's Bosco Verticale and Foster \& Partners' Masdar City, are not sustainable at all from the economic point of view and not very effective with respect to other sustainability dimensions. The economic component, which is a key factor in the social dimension, means that such designs are hardly replicable in other contexts contradicting the statements of their respective designers. This may have happened because the multidimensionality of the project of sustainability was not taken into consideration enough and because they did not consider memory as the material of the project of sustainability. On the other hand, the number of projects that draw on memory as the material of the project of sustainability is growing and keeps involving different branches of learning. However, analyzing such projects the limits deriving from the use of memory have also emerged: first of all, memory can be manipulated and taken advantage of as it is very easy to distort memories. The second limit is that it isn't easy to involve in this process the recipients of the project who also form the collective memory as in the case of Officine Piaggio. The third limit is the lack of a definition of memory linked to sustainability and vice versa.

Scientific research and philosophical speculation on the other hand, strongly suggest the integrative or even the holistic approach, to find sustainable solutions for the ecosystem. Finally, using memory as material for the pro-sustainability project has found, in many areas of intervention, novel applications 
that point to mnemonic processes of recollection and oblivion as new horizons for future research and practical applications. If all this is to serve the cause of sustainability, research must focus on the modalities of mnemonic processes and on the definition of a new conceptual system capable of working as a platform to be shared by all, so that through memory a new awareness with regard to the issue of sustainability can develop. The limit of these considerations lies in the impossibility to define, from the standpoint of only one branch of knowledge, the interconnectivity running between memory and sustainability. A limit that can be overcome if the different branches of knowledge became conscious of the importance of memory and started to define a system of axioms capable of covering a wider range of experiences.

Funding: The research was funded by ARS01_00926 EWAS-An early WArning System for Cultural Heritage-PON PNR2015-2020 project.

Acknowledgments: The author would like to thank Giorgia Sidoti, who collected the data on Casa 100K.

Conflicts of Interest: The author declares no conflict of interest.

\section{References}

1. Coscia, C.; Lazzari, G.; Rubino, I. Values, Memory, and the Role of Exploratory Methods for Policy-Design Processes and the Sustainable Redevelopment of Waterfront Contexts: The Case of Officine Piaggio (Italy). Sustainability 2018, 10, 2989. [CrossRef]

2. Tenuta, P. Indici e modelli di sostenibilità; Franco Angeli: Milano, Italy, 2009.

3. Wells, J. Complexity and Sustainability; Routledge: London, UK; New York, NY, USA, 2013.

4. Alshuwaikhat, H.M.; Abubakar, I. An integrated approach to achieving campus sustainability: Assessment of the current campus environmental management practices. J. Clean. Prod. 2008, 16, 1777-1785. [CrossRef]

5. Bruenig, E.F. Conservation and Management of Tropical Rainforest: An Integrated Approach to Sustainability; CABI: Boston, MA, USA, 2017.

6. Barrett, C.B.; Grizzle, R. A Holistic Approach to Sustainability Based on Pluralism Stewardship. Environ. Ethics 1999, 21, 23-42. [CrossRef]

7. Cuello Nieto, C. Toward a Holistic Approach to the Ideal of Sustainability. Techné Res. Philos. Technol. 1997, 2, 79-83. [CrossRef]

8. Morin, E. Il Metodo. Ordine, Disordine, Organizzazione; Feltrinelli: Milano, Italy, 1994.

9. Berthoz, A. La semplessità; Codice: Torino, Italy, 2011.

10. Sachs, J.D. L'era dello sviluppo sostenibile; Università Bocconi editore: Milano, Italy, 2015.

11. Guido, G.; Massari, S. Lo sviluppo sostenibile. Ambiente, risorse, innovazione, qualità; Franco Angeli: Milano, Italy, 2013.

12. Lanza, A. Lo sviluppo sostenibile; Il Mulino: Bologna, Italy, 2006.

13. Candau, J. La memoria e l'identità; Ipermedium: Napoli, Italy, 2002.

14. Halbwachs, M. La memoria collettiva; Edizioni Unicopli: Milano, Italy, 2001.

15. Nietzsche, F. Sull'utilità e il danno della storia per la vita; Adelphi: Milano, Italy, 2001.

16. Assmann, A. Ricordare. Forma e mutamenti della memoria cultural; il Mulino: Bologna, Italy, 2014.

17. Ricoer, P. La memoria, la storia, l'oblio; Raffaello Cortina: Milano, Italy, 2003.

18. Augé, M. Le forme dell'oblio. Dimenticare per vivere; il Saggiatore: Milano, Italy, 2000.

19. Harrison, R. Forgetting to remember, remembering to forget: Late modern heritage practices, sustainability and the 'crisis' of accumulation of the past. Int. J. Herit. Stud. 2013, 19, 579-595. [CrossRef]

20. Kouchakia, M.; Gino, F. Memories of unethical actions become obfuscated over time. Proc. Natl. Acad. Sci. USA 2016, 113, 6161-6171. [CrossRef]

21. Severino, E. Tecnica e architettura; Raffaello Cortina: Milano, Italy, 2003.

22. Zardini, M. (Against) the Greenwashing of Architecture. New Geogr. Landsc. Energy 2009, 2, 139-147.

23. D'Urso, S. L'architettura non è una lavatrice. La relazione guida la sostenibilità. Bioarchitettura 2013, 80-81, 4-7.

24. Alexander, C. Sustainability and Morphogenesis. In The Birth of a Living World; Schumacher Lecture, Bristol, 30 October 2004; Center for Environmental Structure: Berkeley, CA, USA, 2004.

25. Strassoldo, R. Ecologia; Treccani: Roma, Italy, 2015.

26. Leyton, M. La forma come memoria. Una teoria geometrica dell'architettura; Edilstampa: Roma, Italy, 2009. 
27. Heidegger, M. Costruire abitare pensare. In Martin Heidegger. Saggi e discorsi; Vattimo, G., Ed.; Mursia: Milano, Italy, 1976; pp. 96-108.

28. Heidegger, M. ... poeticamente abita l'uomo ... . In Martin Heidegger. Saggi e discorsi; Vattimo, G., Ed.; Mursia: Milano, Italy, 1976; pp. 125-138.

29. Dal Pozzolo, L. Il patrimonio culturale tra memoria e future; Editrice Bibliografica: Milano, Italy, 2018.

30. Blake, A. President Trump's full Washington Post Interview Transcript, Annotated. The Washington Post, 28 November 2018. Available online: https:/www.washingtonpost.com/politics/2018/11/27/presidenttrumps-full-washington-post-interview-transcript-annotated/(accessed on 10 January 2020).

31. Serrao, G. Perché Trump ha cambiato idea sul cambiamento climatico. AGI. 12 June 2019. Available online: https://www.agi.it/blog-italia/energia-e-sostenibilta/trump_cambiamento_climatico-5638774/post/ 2019-06-12/ (accessed on 10 January 2020).

32. Zichichi, A. Meteorology and Climate: Problems and Expectations. Climate Change and Development International Conference. Pontifical Council for Justice and Peace. The Vatican. 26-27 April 2007. Available online: https:/www.climalteranti.it/wp-content/uploads/2017/09/ZICHICHI_METEOROLOGYAND-CLIMATE2.pdf (accessed on 10 January 2020).

33. Zichichi, A. Cara Greta, studia: Inquinamento e clima sono cose diverse. Il Giornale, 30 settembre 2019. Available online: http://www.ilgiornale.it/news/cronache/cara-greta-studia-inquinamento-e-clima-sonocose-diverse-1760441.html- (accessed on 10 January 2020).

34. Dupuy, J.P. Per un catastrofismo illuminato. Quando l'impossibile è certo; Medusa edizioni: Milano, Italy, 2011.

35. Zizek, S. Censorship Today: Violence, or Ecology, a New Opium for the Masses. Available online: https://www.lacan.com/zizecology1.htm (accessed on 10 January 2020).

36. Francesco. Lettera enciclica Laudato si'. Sulla cura della casa commune; Libreria editrice vaticana: Città del Vaticano, Vatican, 2015.

37. Latouche, S. Breve trattato sulla decrescita serena; Bollati Boringhieri: Torino, Italy, 2008.

38. Schwartzman, D. A Critique of Degrowth and its Politics. Capital. Nat. Soc. 2012, 23, 119-125. [CrossRef]

39. Kallis, G.; March, H. Imaginaries of Hope: The Utopianism of Degrowth. Ann. Assoc. Am. Geogr. 2016, 105, 360-368. [CrossRef]

40. Bauman, Z. Vite di scarto; Laterza: Roma-Bari, Italy, 2019.

41. Bauman, Z. Modus vivendi. Inferno e utopia del mondo liquido; Laterza: Roma-Bari, Italy, 2019.

42. Balzani, V. Tre tappe verso la sostenibilità. Bioarchitettura 2019, 117, 2-5.

43. Balzani, V. Saving the planet and the human society: Renewable energy, circular economy, sobriety. Substantia 2019, 3, 9-15.

44. Beatley, T. Biophilic Cities. Integrating Nature into Urban Design and Planning; Island Press/Center for Resource Economics: Washington, DC, USA, 2011.

45. Marrone, G. Addio alla natura; Einaudi: Torino, Italy, 2011.

46. Mangold, N.; Costard, F.; Forget, F. Debris flows over sand dunes on Mars: Evidence for liquid water. J. Geophys. Res. Atmos. 2003, 108. [CrossRef]

47. Gerber, A. Greener than Architecture! (Towards a sustainable discourse on unsustainability). J. Spéciale'Z 2010, 1, 72-79.

48. Latour, B. Disinventare la modernità; Elèuthera: Milano, Italy, 2008.

49. Rudofsky, B. Architecture Without Architects. A Short Introduction to Non-Pedigreed Architecture; Museum of Modern Art: New York, NY, USA, 1964.

50. May, J.; Reid, A. Architettura senza architetti. Guida alle costruzioni spontanee di tutto il mondo; Rizzoli: Milano, Italy, 2010.

51. Harvey, D. La crisi della modernità; Il Saggiatore: Milano, Italy, 1993.

52. Gauchet, M. Il disincanto del mondo. Una storia politica della religion; Einaudi: Torino, Italy, 1992.

53. Spaemann, R. La diceria immortale. La questione di Dio o l'inganno della modernità; Cantagalli: Siena, Italy, 2008.

54. Cassano, F. Modernizzare stanca. Perdere tempo, guadagnare tempo; Il Mulino: Bologna, Italy, 2001.

55. Ruskin, J. Le sette lampade dell'architettura; Jaca Book: Milano, Italy, 1997.

56. Script Editorial Board. Energia; Script: Bologna, Italy, 2010.

57. Vefago, L.M.H.; Avellaneda, J. The unsustainability of sustainable architecture. In Proceedings of the W096-Special Track 18th CIB World Building Congress, Salford, UK, 10-13 May 2010; pp. 212-223. Available online: https://www.irbnet.de/daten/iconda/CIB18874.pdf (accessed on 10 January 2020). 
58. Martek, I.; Hosseini, M.R.; Shrestha, A.; Zavadskas, E.K.; Seaton, S. The Sustainability Narrative in Contemporary Architecture: Falling Short of Building a Sustainable Future. Sustainability 2018, 10, 981. [CrossRef]

59. Li, Z.; Hanni, W. Il Sieeb a Pechino +5. Il Giornale dell'architettura. 2012. Available online: https: //ilgiornaledellarchitettura.com/web/2012/01/03/il-sieeb-a-pechino-5-di-zhang-li-wang-hanni (accessed on 10 January 2020).

60. Corsolini, L. Mario Cucinella, il mio Piano Casa. WIRED 2009, 3, 54-63.

61. European Commission's Science and Knowledge Service. Photovoltaic Geographical Information System (PVGIS). Available online: http://re.jrc.ec.europa.eu/pvgis/apps4/pvest.php (accessed on 10 January 2020).

62. Idealista Editorial Board. Quanto sono scesi i prezzi delle case dal 2007 al 2016 analisi delle grandi città. Available online: https://www.idealista.it/news/immobiliare/residenziale/2017/04/10/122690-quanto-sonoscesi-i-prezzi-delle-case-dal-2007-al-2016-analisi-delle-grandi-citta (accessed on 10 January 2020).

63. Cribari, V. Ecologie per il progetto contemporaneo: Tra aspettative e metodo. Sentieri urbani 2016, 19, 46-49.

64. Kohlstedt, K. Renderings vs. Reality: The Improbable Rise of Tree-Covered Skyscrapers. 99percentinvisible. 2016. Available online: https:/99percentinvisible.org/article/renderings-vs-reality-rise-tree-covered-skyscrapers/ (accessed on 10 January 2020).

65. Le Goff, J. Storia e Memoria; Einaudi: Torino, Italy, 1982.

66. Pallasmaa, J. The Eyes of the Skin: Architecture and the Senses; John Wiley \& Sons: Chichester, UK, 2012.

67. Uekötter, F. Ökologische Erinnerungsorte; Vandenhoeck \& Ruprecht: Göttingen, Germany, 2014.

68. Nora, P. Les lieux de la mémoire. La République; Gallimard: Paris, France, 1984.

69. Reed, K.; Ryan, P. Lessons from the past and the future of food. World Archaeol. 2019, 51, 1-16. [CrossRef]

70. Matous, P.; Todo, Y. An experiment in strengthening the networks of remote communities in the face of environmental change: Leveraging spatially distributed environmental memory. Reg. Environ. Chang. 2018, 18, 1741-1752. [CrossRef]

71. Bernardo, M.; De Pascale, F. A Study on Memory Sites Perception in Primary School for Promoting the Urban Sustainability Education: A Learning Module in Calabria (Southern Italy). Sustainability 2019, 11, 6379. [CrossRef]

72. Barthel, S.; Folke, C.; Colding, J. Social-ecological memory in urban gardens-Retaining the capacity for management of ecosystem services. Glob. Environ. Chang. 2010, 20, 255-265. [CrossRef]

73. Garde-Hansen, J.; McEwen, L.; Holmes, A.; Jones, O. Sustainable flood memory: Remembering as resilience. Mem. Stud. 2017, 10, 384-405. [CrossRef]

74. Stedman, L. Scrivere sull'acqua: Il volto mutevole della comunicazione. In Comunicazione sull'acqua: Analisi di strategie e campagne del settore idrico; Herve-Bazin, C., Ed.; IWA Publishing: London, UK, 2014; pp. 125-126.

75. Ardakani, M.K.; Oloonabadi, S.S.A. Collective memory as an efficient agent in sustainable urban conservation. Procedia Eng. 2011, 21, 985-988. [CrossRef]

76. Choay, F. L'invenzione del patrimonio storico. Rassegna di architettura e urbanistica 1993, 80/81, 7-11.

77. D’Urso, S. Memoria e processo costruttivo. Il ristorante "Las Cupulas" con la tecnica earthbag. Bioarchitettura 2014, 86, 36-43.

78. Kattan, E. Il dovere della memoria; Ipermedium: Napoli, Italy, 2004.

79. Settis, S. Paesaggio Costituzione cemento. La battaglia per l'ambiente contro il degrado civile; Einaudi: Torino, Italy, 2010.

80. Settis, S. Se Venezia muore; Einaudi: Torino, Italy, 2014.

81. Adorno, T. Minima Moralia: Reflections from Damaged Life; Verso: London, UK; New York, NY, USA, 2005.

82. Deleuze, G. Difference and Repetition; Columbia University Press: New York, NY, USA, 1994.

83. Heisenberg, W. Physics and Philosophy. The Revolution in Modern Science; George Allen \& Unwin Ltd: London, UK, 1971.

(C) 2020 by the author. Licensee MDPI, Basel, Switzerland. This article is an open access article distributed under the terms and conditions of the Creative Commons Attribution (CC BY) license (http://creativecommons.org/licenses/by/4.0/). 